\title{
Intimate partner violence among HIV-serodiscordant couples in Durban, South Africa
}

\author{
S Mashaphu, ${ }^{1} \mathrm{MB} \mathrm{ChB}, \mathrm{MMed}(\mathrm{Psych}), \mathrm{FC}$ Psych (SA); G E Wyatt, ${ }^{2} \mathrm{PhD}$; E Gomo, ${ }^{3} \mathrm{PhD} ; \mathbf{A}$ Tomita, ${ }^{4,5} \mathrm{PhD}$ \\ ${ }^{1}$ Department of Psychiatry, School of Clinical Medicine, Nelson R Mandela School of Medicine, College of Health Sciences, University of KwaZulu- \\ Natal, Durban, South Africa \\ ${ }^{2}$ Department of Psychiatry and Biobehavioral Sciences, University of California, Los Angeles, USA \\ ${ }^{3}$ School of Nursing and Public Health, College of Health Sciences, University of KwaZulu-Natal, Durban, South Africa \\ ${ }^{4}$ KwaZulu-Natal Research Innovation and Sequencing Platform (KRISP), College of Health Sciences, University of KwaZulu-Natal, Durban, South Africa \\ ${ }^{5}$ Centre for Rural Health, School of Nursing and Public Health, College of Health Sciences, University of KwaZulu-Natal, Durban, South Africa
}

Corresponding author: S Mashaphu (mashaphus@ukzn.ac.za)

\begin{abstract}
Background. South Africa (SA) has a high prevalence rate of intimate partner violence (IPV) and HIV, both of which can be exacerbated further by HIV serodiscordancy in the couple dyad. Further exploration of the discordancy sidedness in known mediating factors, such as alcohol abuse risk and post-traumatic stress (PTS), is required.

Objectives. To investigate the extent of and gender differences in IPV, alcohol abuse risk and PTS symptoms among HIV-serodiscordant couples in Durban, SA, and to analyse these further with regard to female HIV serostatus.

Methods. A cross-sectional analysis of data on 30 serodiscordant couples was conducted at the point of enrolment into a pilot study of an HIV risk reduction intervention. The statistical procedure for a dependent small sample was applied to examine gender differences in IPV, alcohol use and PTS symptoms among HIV-serodiscordant couples.

Results. The woman was HIV-positive in $18(60.0 \%)$ of the 30 serodiscordant couples enrolled. Exposure to IPV differed significantly between men $(28.6 \%)$ and women $(89.3 \%)$ (proportional difference $-0.61,95 \%$ confidence interval (CI) $-0.82--0.39$ ). The Wilcoxon signed-rank test showed that PTS symptom scores differed significantly between men (median 22, interquartile range (IQR) 23 ) and women (median 44, IQR 28) ( $p=0.03$ ). When the above analysis was stratified by female HIV serostatus, significant gender differences were found in IPV and PTS in the couples where the woman was HIV-positive. There were no significant gender differences for alcohol abuse risk.

Conclusions. The findings demonstrated high levels of IPV in HIV-serodiscordant couples and a significant gender difference in mental health risk such as PTS in such relationships, particularly where the woman was HIV-positive. HIV intervention programmes should address gender-based violence and inequity among heterosexual couples.
\end{abstract}

S Afr Med J 2018;108(11):960-964. DOI:10.7196/SAMJ.2018.v108i11.13095

Intimate partner violence (IPV) is an extensive social and health challenge that cuts across ethnic, cultural and socioeconomic boundaries. ${ }^{[1,2]} \mathrm{IPV}$ in South Africa (SA) is an important public health issue that requires urgent attention. A national epidemiological study estimates that $50.3 \%$ of female homicides were from IPV ${ }^{[3]}$ Another major study conducted in SA, a country with one of the highest burdens of HIV infection in the world, ${ }^{[4]}$ reported IPV to be an important influence on women's risk of HIV infection. ${ }^{[5]}$

Research from the USA has shown that women who experience IPV report increased risk-taking behaviours for HIV acquisition/ transmission. ${ }^{[6,7]}$ While this evidence suggests that IPV and gender inequity may be risk factors for HIV infection, very few studies in SA have explored the extent of gender differences in IPV in serodiscordant relationships. In these relationships, one partner is infected with HIV while the other is not, a situation that is very common in sub-Saharan Africa. ${ }^{[8]}$ In discordant couples, the HIVnegative member is at extremely high risk of HIV infection; ageadjusted rate ratios can be as high as 12 for men and 106 for women compared with their counterparts in relationships where both partners are HIV-negative. ${ }^{[9]}$

Discordant relationships are subject to several challenges, particularly increased stress among individuals who are told that they are HIV-positive. Sources of conflict may include how the illness was acquired, the possibility of transmission to the uninfected partner, and concerns about procreation. ${ }^{[10]}$ Although the exact figures are not known, there are many cases of previously peaceful relationships that became abusive after HIV status disclosure. ${ }^{[11]}$

IPV encompasses various forms of physical, verbal and emotional abuse. ${ }^{[12-14]}$ According to the Centers for Disease Control and Prevention in the USA, IPV is defined as 'physical, sexual, or psychological harm by a current or former partner or spouse. ${ }^{[12]}$ Few studies have examined the perceptions of those involved in partner violence to understand why the violence occurred. Insight into the perceptions of both male and female perpetrators and victims can provide measures of risk factors, such as demographic and victim characteristics, and personal and cultural factors associated with HIV transmission. However, there is evidence to suggest a correlation between IPV, post-traumatic stress disorder (PTSD) and alcohol abuse risk. ${ }^{[15]}$

\section{Objectives}

To investigate the extent of and gender differences in IPV, alcohol abuse risk and post-traumatic stress (PTS) symptoms among HIVserodiscordant couples in Durban, SA, and to analyse these further with regard to female HIV serostatus. 


\section{Methods \\ Sample}

The data were obtained using a cross-sectional, baseline research questionnaire administered to individuals enrolling into an HIV risk reduction trial that aimed to recruit 30 serodiscordant couples. The study took place in Durban. Data collection and analysis commenced in August 2016, with 30 serodiscordant couples ( $N=60$ participants) being enrolled by the end of November 2017.

\section{Referral patterns}

The study participants were patients attending private healthcare facilities who were referred to a specialist psychiatrist by health professionals who had agreed to refer patients seeking clinical advice, specifically general practitioners, clinical psychologists and specialists in various clinical disciplines. The healthcare providers were approached individually with a brief of the study protocol and provided with information leaflets to distribute to potential participants. After a screening process carried out by the principal investigator, only the eligible serodiscordant couples were recruited to participate.

\section{Ethical considerations}

Participants were included in the study if they were serodiscordant, had been together for $>3$ months, had disclosed their HIV status to their partner, and were self-identified heterosexuals aged $\geq 18$ years. Potential participants were excluded if their status was not disclosed to the partner, if they were seroconcordant, or if they were not willing to participate in research. Participants were informed of the procedures, benefits and potential risks of taking part in this study, and provided informed written consent for the interviews, focus group discussions and blood sample collection. Ethical approval was obtained from the University of KwaZulu-Natal's Biomedical Research Ethics Committee (ref. no. 166/15).

\section{Measures and assessments}

Serodiscordance was confirmed with the most recent enzymelinked immunosorbent assay HIV test result, ${ }^{[16]}$ taken not more than 3 months prior to enrolment for the HIV-negative partner. Participants who had been tested more than 3 months previously were retested following voluntary testing and counselling as part of the study. At first contact, participants were screened for eligibility by the principal investigator, and were then asked to complete a detailed questionnaire comprising sociodemographics, relationship characteristics, general health and quality of life, sexual abuse, alcohol abuse risk and PTS. The questionnaire was completed by each participant individually in the presence of the principal investigator and took an average of 60 minutes.

\section{Measures}

- Sociodemographic characteristics. Participants answered 20 sociodemographic questions on age, level of education, profession, medical insurance and clinical details.

- Relationship characteristics included the length of the relationship, marital status, number of children and living arrangements.

- Intimate partner violence was measured by the 19-item revised Conflict Tactics scale (CTS), ${ }^{[17,18]}$ which established both a history and recent experiences of abuse. Participants were asked whether a current or previous partner had hurt them verbally, physically or sexually in any way. For this study, the CTS was adapted to address violence experienced since the age of 18. If participants answered yes, they were classified as having experienced adult abuse.
- Alcohol abuse risk. Participants were screened for lifetime alcohol dependence using the CAGE criteria $^{[19]}$ (cutting down, annoyance by criticism, guilty feelings and eye-openers), with alcohol problems being denoted by CAGE scores $\geq 2$.

- PTS was screened for using the PTSD Checklist (civilian version), a 17-item self-report measure reflecting Diagnostic and Statistical Manual of Mental Disorders, 4th edition (DSM-IV) symptoms of PTSD in relation to generic 'stressful experiences' that can be used with any population. This version was used because symptom endorsements were not attributed to a specific event. ${ }^{[20,21]}$ A total PTS symptom severity score was calculated by summing the scores (range 17 - 85) from each of the 17 items.

\section{Statistical analysis}

Two analyses were conducted using Stata 15 (StataCorp, USA). The first examined the participants' sociodemographic and clinical details using descriptive statistical methods. For the categorical variables, the numbers and percentages were reported, while for the continuous variables, medians and interquartile ranges (IQRs) were reported, given the small sample size. The second analysis examined gender differences in IPV, alcohol abuse risk and PTS symptoms among HIV-serodiscordant couples, which were further analysed with regard to female HIV serostatus. For categorical outcome variables, we reported the difference in dependent proportions, with significant differences being examined using the asymptotic McNemar test and the McNemar mid- $p$ test. ${ }^{[22]}$ For continuous outcome variables, significant gender differences in the median score were examined using the Wilcoxon signed-rank test.

\section{Results}

The first analysis examined the participants' sociodemographic and clinical details (Table 1 ). In the 30 serodiscordant couples enrolled, $18(60.0 \%)$ of the women were HIV-positive. Approximately half of the male and female participants had been in the current relationship for $>5$ years, and most were employed with grade 12 and a higher qualification.

The second analysis examined gender differences in IPV exposure, alcohol abuse risk and PTS outcome (Table 2). Overall ( $N=30$ couples) there were significant gender differences in IPV and PTS symptoms, but not in alcohol use. Exposure to IPV differed significantly between men $(28.6 \%)$ and women (89.3\%) (dependent proportional difference $0.61,95 \%$ confidence interval (CI) $-0.82--0.39)$. The Wilcoxon signed-rank test showed median PTSD symptom scores to be significantly different between men (22, IQR 23) and women (44, IQR 28) ( $p=0.03)$.

The analyses also examined gender differences in IPV exposure, alcohol abuse risk and PTS outcome based on female HIV serostatus (Tables 3 and 4). Again we found significant gender differences in IPV and PTS symptoms, but not in alcohol use, where the woman was HIV-positive (Table 3). However, where the woman was HIVnegative, we only found significant gender differences in IPV, and not in alcohol use or PTS symptoms (Table 4).

\section{Discussion}

The objective of this study was to investigate the extent of and gender differences in IPV, alcohol abuse risk and PTS symptoms among HIV-serodiscordant couples, and to analyse these further with regard to female HIV serostatus. We found significantly higher levels of IPV and PTS symptoms among women than among men in the HIV-serodiscordant couples, but no gender differences in alcohol abuse risk. When the analysis was stratified based on female HIV 
Table 1. Demographic and clinical characteristics of HIV-serodiscordant couples stratified by female HIV serostatus ${ }^{*}$

\begin{tabular}{|c|c|c|c|c|c|c|}
\hline & \multicolumn{2}{|c|}{ Couples $(N=30)$} & \multicolumn{2}{|c|}{$\begin{array}{c}\text { Couples with HIV- } \\
\text { positive women }(N=18)\end{array}$} & \multicolumn{2}{|c|}{$\begin{array}{l}\text { Couples with HIV- } \\
\text { positive men }(N=12)\end{array}$} \\
\hline & Women, $n(\%)$ & Men, $n(\%)$ & $\begin{array}{l}\text { HIV-positive } \\
\text { women, } n(\%)\end{array}$ & $\begin{array}{l}\text { HIV- } \\
\text { negative } \\
\text { men, } n(\%)\end{array}$ & $\begin{array}{l}\text { HIV-positive } \\
\text { men, } n(\%)\end{array}$ & $\begin{array}{l}\text { HIV- } \\
\text { negative } \\
\text { women, } n(\%)\end{array}$ \\
\hline \multicolumn{7}{|l|}{ Demographic characteristics } \\
\hline \multicolumn{7}{|l|}{ Age category (years), $n$ (\%) } \\
\hline $18-29$ & $4(13.3)$ & $3(10.0)$ & $3(16.7)$ & $2(11.1)$ & $1(8.3)$ & $1(8.3)$ \\
\hline $30-49$ & $23(76.7)$ & $22(73.3)$ & $15(83.3)$ & $14(77.8)$ & $8(66.7)$ & $8(66.7)$ \\
\hline $50-64$ & $3(10.0)$ & $5(16.7)$ & 0 & $2(11.1)$ & $3(25.0)$ & $3(25.0)$ \\
\hline \multicolumn{7}{|l|}{ Educational attainment, $n(\%)$} \\
\hline Grade 8 & $3(11.5)$ & $4(14.3)$ & $2(12.5)$ & $2(11.8)$ & $2(18.2)$ & $1(10.0)$ \\
\hline $\begin{array}{l}\text { Grade } 12 \text { and higher (highest level of } \\
\text { education attained) }\end{array}$ & $23(88.5)$ & $24(85.7)$ & $14(87.5)$ & $15(88.2)$ & $9(81.8)$ & $9(90.0)$ \\
\hline \multicolumn{7}{|l|}{ Employment status, $n(\%)$} \\
\hline Unemployed & $6(20.7)$ & $2(7.1)$ & $3(17.7)$ & $1(5.9)$ & $1(9.1)$ & $3(25.0)$ \\
\hline Employed full/part time & $23(79.3)$ & $26(92.9)$ & $14(82.4)$ & $16(94.1)$ & $10(90.9)$ & $9(75.0)$ \\
\hline \multicolumn{7}{|l|}{ Married, $n(\%)$} \\
\hline No & $15(50.0)$ & $14(46.7)$ & $12(66.7)$ & $11(61.1)$ & $3(25.0)$ & $3(25.0)$ \\
\hline Yes & $15(50.0)$ & $16(53.3)$ & $6(33.3)$ & $7(38.9)$ & $9(75.0)$ & $9(75.0)$ \\
\hline \multicolumn{7}{|l|}{ Separated from spouse, $n(\%)$} \\
\hline No & $23(85.2)$ & $24(85.7)$ & $14(87.5)$ & $15(83.3)$ & $9(90.0)$ & $9(81.8)$ \\
\hline Yes & $4(14.8)$ & $4(14.3)$ & $2(12.5)$ & $3(16.7)$ & $1(10.0)$ & $2(18.2)$ \\
\hline \multicolumn{7}{|l|}{ Married to study partner, $n(\%)$} \\
\hline No & $12(41.4)$ & $12(40.0)$ & $10(58.8)$ & $10(55.6)$ & $2(16.7)$ & $2(16.7)$ \\
\hline Yes & $17(58.6)$ & $18(60.0)$ & $7(41.2)$ & $8(44.4)$ & $10(83.3)$ & $10(83.3)$ \\
\hline \multicolumn{7}{|l|}{$\begin{array}{l}\text { Length of relationship with study partner } \\
\text { (years), } n(\%)\end{array}$} \\
\hline$\leq 5$ & $15(50.0)$ & $14(46.7)$ & $8(44.4)$ & $8(44.4)$ & $6(50.0)$ & $6(58.3)$ \\
\hline$>5$ & $15(50.0)$ & $16(53.3)$ & $10(55.6)$ & $10(55.6)$ & $6(50.0)$ & $5(41.7)$ \\
\hline \multicolumn{7}{|l|}{ Clinical characteristics } \\
\hline \multicolumn{7}{|l|}{ Alcohol abuse risk, $n(\%)$} \\
\hline No & $22(95.7)$ & $23(79.3)$ & $13(92.9)$ & $14(77.8)$ & $9(81.8)$ & $9(100.0)$ \\
\hline Yes & $1(4.3)$ & $6(20.7)$ & $1(7.1)$ & $4(22.2)$ & $2(18.2)$ & $0(0.0)$ \\
\hline Trauma symptomatology, median (IQR) & $40(28)$ & $22(23)$ & $42.5(12)$ & $21(18)$ & $33.5(27.5)$ & $37(39.6)$ \\
\hline \multicolumn{7}{|l|}{ Exposure to IPV, $n(\%)$} \\
\hline No & $3(10.7)$ & $21(70.0)$ & $1(5.9)$ & $12(66.7)$ & $9(75.0)$ & $2(18.2)$ \\
\hline Yes & $25(89.3)$ & $9(30.0)$ & $16(94.1)$ & $6(33.3)$ & $3(25.0)$ & $9(81.8)$ \\
\hline
\end{tabular}

serostatus, we found gender differences in PTS symptoms in the serodiscordant couples where the woman was HIV-positive, but not in women who were HIV-negative. Our study highlights the high levels of IPV in women overall, as well as differences in mental health challenges according to female HIV serostatus.

\section{Gender and IPV}

In the context of HIV serodiscordance, it appears that there is a direct risk of the non-infected partner becoming infected when IPV is present. ${ }^{[23]} \mathrm{IPV}$ is generally perpetrated by male partners, most often a spouse or someone emotionally close to the woman, and a study has even reported that some HIV-positive males deliberately infect their HIV-negative partners. ${ }^{[1]}$ In this SA sample, the overwhelming majority (94.1\%) of the HIV-positive women reported IPV - a higher figure than that for the HIV-negative women, although this difference was not statistically significant, possibly owing to the small sample size. Other studies support similar findings, with
Shuaib et al. ${ }^{[24]}$ in Uganda reporting that HIV-positive women in discordant relationships were at a higher risk of sexual violence than those who were uninfected or in negative concordant unions.

\section{Gender and PTS}

In this study, we included screening for PTSD symptomatology as a possible consequence of previous or ongoing exposure to IPV and for its long-term effects on the mental health of the participants. We found significantly higher levels of PTSD in women, specifically those who were HIV-positive, which highlights the need to screen and address trauma symptoms in other populations of serodiscordant couples during couples voluntary counselling and testing. Previous intervention studies on serodiscordant couples have demonstrated a decrease in HIV transmission protective behaviours in couples where one or both partners had clinically significant symptoms of PTSD. ${ }^{[25]}$ These findings suggest that the success of sexual risk reduction interventions may be attenuated and compromised by the presence of 
Table 2. Comparison of clinical characteristics of HIV-serodiscordant couples $(N=30)$

\begin{tabular}{|c|c|c|c|c|c|}
\hline & Female IPV+ & Female IPV- & Total & & \\
\hline Male IPV+ & 8 & 0 & 8 & Male IPV+ proportion & 0.29 \\
\hline Male IPV- & 17 & 3 & 20 & Female IPV+ proportion & 0.89 \\
\hline \multirow[t]{4}{*}{ Total } & 25 & 3 & 28 & Difference in proportion & $-0.61(95 \%$ CI $-0.82--0.39)$ \\
\hline & & & & Asymptotic McNemar test & $p<0.01$ \\
\hline & & & & McNemar mid- $p$ test & $p<0.01$ \\
\hline & Female CAGE+ & Female CAGE- & Total & & \\
\hline Male CAGE+ & 1 & 5 & 6 & Male CAGE+ proportion & 0.26 \\
\hline Male CAGE- & 0 & 17 & 17 & Female CAGE+ proportion & 0.04 \\
\hline \multirow[t]{3}{*}{ Total } & 1 & 22 & 23 & Difference in proportion & $0.22(95 \%$ CI $0.01-0.43)$ \\
\hline & & & & Asymptotic McNemar test & $p=0.03$ \\
\hline & & & & McNemar mid- $p$ test & $p=0.03$ \\
\hline Male median PTS score & 22 (IQR 23) & & & Wilcoxon signed-rank test & $p=0.03$ \\
\hline Female median PTS score & 40 (IQR 28) & & & & \\
\hline
\end{tabular}

Table 3. Comparison of clinical characteristics in 18 couples in which the woman was HIV-positive $(N=18)$

\begin{tabular}{|c|c|c|c|c|c|}
\hline & Female IPV+ & Female IPV- & Total & & \\
\hline Male IPV+ & 5 & 0 & 5 & Male IPV+ proportion & 0.29 \\
\hline Male IPV- & 11 & 1 & 12 & Female IPV+ proportion & 0.94 \\
\hline \multirow[t]{4}{*}{ Total } & 16 & 1 & 17 & Difference in proportion & $-0.65(95 \% \mathrm{CI}-0.93--0.36)$ \\
\hline & & & & Asymptotic McNemar test & $p<0.01$ \\
\hline & & & & McNemar mid- $p$ test & $p<0.01$ \\
\hline & Female CAGE+ & Female CAGE- & Total & & \\
\hline Male CAGE+ & 1 & 3 & 4 & Male CAGE+ proportion & 0.29 \\
\hline Male CAGE- & 0 & 10 & 10 & Female CAGE+ proportion & 0.07 \\
\hline \multirow[t]{3}{*}{ Total } & 1 & 13 & 14 & Difference in proportion & $0.21(95 \% \mathrm{CI}-0.07-0.50)$ \\
\hline & & & & Asymptotic McNemar test & $p=0.08$ \\
\hline & & & & McNemar mid- $p$ test & $p=0.13$ \\
\hline Male median PTS score & 21.0 (IQR 18) & & & Wilcoxon signed-rank test & $p=0.02$ \\
\hline Female median PTS score & 42.5 (IQR 12) & & & & \\
\hline
\end{tabular}

Table 4. Comparison of clinical characteristics in couples in which the woman was HIV-negative $(N=12)$

\begin{tabular}{|c|c|c|c|c|c|}
\hline & Female IPV+ & Female IPV- & Total & & \\
\hline Male IPV+ & 3 & 0 & 3 & Male IPV+ proportion & 0.27 \\
\hline Male IPV- & 6 & 2 & 8 & Female IPV+ proportion & 0.82 \\
\hline \multirow[t]{4}{*}{ Total } & 9 & 2 & 11 & Difference in proportion & $-0.55(95 \%$ CI $-0.93--0.16)$ \\
\hline & & & & Asymptotic McNemar test & $p<0.01$ \\
\hline & & & & McNemar mid- $p$ test & $p<0.02$ \\
\hline & Female CAGE+ & Female CAGE- & Total & & \\
\hline Male CAGE+ & 0 & 2 & 2 & Male CAGE+ proportion & 0.22 \\
\hline Male CAGE- & 0 & 7 & 7 & Female CAGE+ proportion & 0.00 \\
\hline \multirow[t]{3}{*}{ Total } & 0 & 9 & 9 & Difference in proportion & $0.22(95 \%$ CI $-0.16-0.60)$ \\
\hline & & & & Asymptotic McNemar test & $p=0.16$ \\
\hline & & & & McNemar mid- $p$ test & $p=0.25$ \\
\hline Male median PTS score & 33.5 (IQR 27.5) & & & Wilcoxon signed-rank test & $p=0.72$ \\
\hline Female median PTS score & 37.0 (IQR 29.5) & & & & \\
\hline
\end{tabular}


physical or sexual trauma histories and residual mental health issues, such as PTSD.

\section{Gender and alcohol abuse risk}

Most studies correlate IPV with alcohol use, but very few have examined its prevalence or impact in serodiscordant relationships. Our results show that only $20.7 \%$ of participants (both male and female) reported alcohol use. However, social desirability bias, non-disclosure and under-reporting of alcohol use could have been responsible for these low rates, as a common symptom of alcoholism is denial. ${ }^{[26]}$ Further studies are needed to examine the prevalence of alcohol use in serodiscordant couples and its role in IPV.

\section{Study limitations}

Our study had a number of limitations. Firstly, the small crosssectional study sample makes generalisation difficult, and some questions regarding the temporal sequence of events await further research. Secondly, the study sample was drawn from a private practice setting and may not be generalisable to the majority of the SA population, who use public sector facilities. Finally, our clinical sample may not be fully representative of HIV-serodiscordant couples, particularly those who are not aware of their serodiscordant status.

\section{Conclusions}

Notwithstanding the limitations of this study, we have provided insight into certain aspects of IPV, alcohol use and PTS among HIV-serodiscordant couples. HIV counselling and testing should support capacitation to address issues related to gender inequity for couples who are HIV-discordant, especially where the woman is HIVpositive. Policies, interventions and programmes for HIV prevention must address these risk factors and allocate appropriate resources.

Declaration. This publication was a requirement for a $\mathrm{PhD}$ for the first author, SM.

Acknowledgements. A special thank you to the general practitioners and specialists who referred participants to this programme. We wish to acknowledge the contributions of Prof. Moses Chimbari and Prof. Benn Sartorius for their thoughtful input to the manuscript.

Author contributions. SM conceived the study. GEW contributed to the conception and design of the study. AT did the statistical analysis. SM and AT drafted the article. All authors provided critical input to the writing of the article. The publication of the article was approved by all authors. Funding. This study was supported by a student exchange fellowship grant from the National Institutes of Health (NIH) and the University of California, Los Angeles Phodiso Program (MH093230), implementing EBAN, an evidence-based intervention for serodiscordant couples. AT was supported by a South African Medical Research Council (SA MRC) flagship grant (MRC-RFAUFSP-01-2013/UKZN HIVEPI). The content is solely the responsibility of the authors and does not necessarily represent the official views of the NIH or the SA MRC. We also acknowledge the contribution of the University of KwaZulu-Natal through a research development grant from the College of Health Sciences.

Conflicts of interest. None.

1. Flynn A, Graham K. 'Why did it happen?' A review and conceptual framework for research on perpetrators' and victims' explanations for intimate partner violence. Aggress Violent Behav 2010;15(3):239-251. https://doi.org/10.1016/j.avb.2010.01.002

2. Gordon C. Intimate partner violence is everyone's problem, but how should we approach it in a clinical setting? S Afr Med J 2016;106(10):962-965. https://doi.org/10.7196/SAMJ.2016.v106i10.11408

3. Abrahams N, Jewkes R, Martin LJ, Mathews S, Vetten L, Lombard C. Mortality of women from intimate Abrahams N, Jewkes R, Martin LJ, Mathews S, Vetten L, Lombard C. Mortality of women from intimate
partner violence in South Africa: A national epidemiological study. Violence Vict 2009;24(4):546. partner violence in South Africa: A nation
https://doi.org/10.1891/0886-6708.24.4.546

4. Joint United Nations Programme on HIV/AIDS. The GAP Report. Geneva: UNAIDS, 2014.

5. Jewkes RK, Dunkle K, Nduna M, Shai N. Intimate partner violence, relationship power inequity, and incidence of HIV infection in young women in South Africa: A cohort study. Lancet 2010;376(9734):4148. https://doi.org/10.1016/S0140-6736(10)60548-X

6. El-Bassel N, Gilbert L, Wu E, et al. Intimate partner violence prevalence and HIV risks among women receiving care in emergency departments: Implications for IPV and HIV screening. Emerg Med J 2007;24(4):255-259. https://doi.org/10.1001/archinternmed.2010.261

7. El-Bassel N, Gilbert L, Witte S, Wu E, Chang M. Intimate partner violence and HIV among druginvolved women: Contexts linking these two epidemics - challenges and implications for prevention and treatment. Subst Use Misuse 2011;46(2-3):295-306. https://doi.org/10.1136/emj.2006.041541

8. Brandon LG, Guy de B, Carey F. HIV-1-discordant couples in sub-Saharan Africa: Explanation and implications for high rates of discordancy. Curr HIV Res 2007;5(4):416-429. https://doi. org/10.2174/157016207781023992

9. Carpenter LM, Kamali A, Ruberantwari A, Malamba SS, Whitworth JA. Rates of HIV-1 transmission within marriage in rural Uganda in relation to the HIV sero-status of the partners. AIDS 1999;13(9):1083-1089.

10. Emusu D, Ivankova N, Jolly P, et al. Experience of sexual violence among women in HIV discordant unions after voluntary HIV counselling and testing: A qualitative critical incident study in Uganda. AIDS Care 2009;21(11):1363-1370. https://doi.org/10.1080/09540120902883077

11. Ware NC, Wyatt MA, Haberer JE, et al. What's love got to do with it? Explaining adherence to oral antiretroviral pre-exposure prophylaxis (PrEP) for HIV serodiscordant couples. J Acquir Immune Defic Syndr 2012;59(5):463-468. https://doi.org/10.1097/QAI.0b013e31824a060b

12. Centers for Disease Control and Prevention. Intimate partner violence. https://www.cdc.gov violenceprevention/intimatepartnerviolence/index.html (accessed 16 April 2018).

13. World Health Organization. Intimate partner violence. http://www.who.int/violence_injury_ prevention/violence/world_report/factsheets/en/ipvfacts.pdf (accessed 16 April 2018)

14. Breiding MJ, Basile KC, Smith SG, Black MC, Mahendra RR. Intimate Partner Violence Surveillance Uniform Definitions and Recommended Data Elements. Version 2.0. Atlanta, Ga: National Center fo Injury Prevention and Control, Centers for Disease Control and Prevention, 2015.

15. Kaysen D, Dillworth TM, Simpson T, Waldrop A, Larimer ME, Resick PA. Domestic violence and alcohol use: Trauma-related symptoms and motives for drinking. Addict Behav 2007;32(6):1272-1283. https://doi.org/10.1016/j.addbeh.2006.09.007

16. Urassa WK, Bredberg-Rådén U, Mbena E, et al. Alternative confirmatory strategies in HIV-1 antibody testing. J Acquir Immune Defic Syndr 1992;5(2):170-176.

17. Straus MA. Measuring intrafamily conflict and violence: The conflict tactics (CT) scales. J Marriage Fam 1979:41(1):75-88. https://doi.org/10.2307/351733

18. Straus MA, Hamby SL, Boney-McCoy S, Sugarman DB. The revised conflict tactics scales (CTS2) development and preliminary psychometric data. J Fam Issues 1996;17(3):283-316.

19. King M. At risk drinking among general practice attenders: Validation of the CAGE questionnaire. . King M. At risk drinking among general practice attenders: Validation of the
Psychol Med 1986;16(1):213-217. https://doi.org/10.1017/S0033291700002658

20. Ruggiero KI, Ben KD, Scotti JR, Rabalais AE. Psychometric properties of the PTSD checklist - civilian Ruggiero KJ, Ben KD, Scotti JR, Rabalais AE. Psychometric properties of the PTSD che
version. J Trauma Stress 2003;16(5):495-502. https://doi.org/10.1023/A:1025714729117

21. Weathers FW, Litz BT, Herman D, Huska J, Keane T. The PTSD checklist - civilian version (PCL-C). Boston, Mass: National Center for PTSD, 1994

22. Fagerland MW, Lydersen S, Laake P. The McNemar test for binary matched-pairs data: Mid- $p$ and asymptotic are better than exact conditional. BMC Med Res Methodol 2013;13(1):91. https://doi. org/10.1186/1471-2288-13-91

23. Heise L, Ellsberg M, Gottmoeller M. A global overview of gender-based violence. Int J Gynaecol Obstet 2002(S1);78:S5-S14. https://doi.org/10.1016/S0020-7292(02)00038-3

24. Shuaib Faisal MB, Ehiri John E, Jolly P, et al. Sexual violence and associated factors among women in HIV discordant and concordant relationships in Uganda. Int J Adolesc Med Health 2012;24(2):125133. https://doi.org/10.1515/ijamh.2012.019

25. Wyatt GE, Loeb TB, Williams JK, Zhang M, Davis TD. A case study of sexual abuse and psychological correlates among an HIV-serodiscordant couple. Couple Family Psychol 2012;1(2):146. https://doi. org $/ 10.1037 / 20028773$

26. Del Boca FK, Noll JA. Truth or consequences: The validity of self-report data in health services research on addictions. Addiction 2000;95(11s3):347-360. https://doi.org/10.1046/j.1360-0443.95.11s3.5.x 